\title{
Assessment of violet-blue color formation in Phalaenopsis orchids
}

Che-Yu Liang ${ }^{1}$, Krishna Preethi Rengasamy ${ }^{1}$, Li-Min Huang ${ }^{1}$, Chia-Chi Hsu ${ }^{1 *}$, Mei-Fen Jeng ${ }^{2}$, Wen-Huei Chen ${ }^{1,2}$ and Hong-Hwa Chen ${ }^{1,2,3^{*}}$ (D)

\begin{abstract}
Background: Phalaenopsis represents an important cash crop worldwide. Abundant flower colors observed in Phalaenopsis orchids range from red-purple, purple, purple-violet, violet, and violet-blue. However, violet-blue orchids are less bred than are those of other colors. Anthocyanin, vacuolar pH and metal ions are three major factors influencing flower color. This study aimed to identify the factors causing the violet-blue color in Phalaenopsis flowers and to analyze whether delphinidin accumulation and blue pigmentation formation can be achieved by transient overexpression of heterologous $\mathrm{F}^{\prime} \mathrm{S}^{\prime} \mathrm{H}$ in Phalaenopsis.

Results: Cyanidin-based anthocyanin was highly accumulated in Phalaenopsis flowers with red-purple, purple, purple-violet, and violet to violet-blue color, but no true-blue color and no delphinidin was detected. Concomitantly, the expression of PeF3'H (Phalaenopsis equestrsis) was high, but that of PhF3'5'H (Phalaenopsis hybrid) was low or absent in various-colored Phalaenopsis flowers. Transient overexpression of DgF3'5'H (Delphinium grandiflorum) and PeMYB2 in a white Phalaenopsis cultivar resulted a 53.6\% delphinidin accumulation and a novel blue color formation. In contrast, transient overexpression of both PhF3'5'H and PeMYB2 did not lead to delphinidin accumulation. Sequence analysis showed that the substrate recognition site 6 (SRS6) of PhF3'5'H was consistently different from DgF3'5'Hs at positions 5, 8 and 10. Prediction of molecular docking of the substrates showed a contrary binding direction of aromatic rings (B-ring) with the SRS6 domain of $\mathrm{DgF}^{\prime} 5^{\prime} \mathrm{H}$ and PhF3' $5^{\prime} \mathrm{H}$. In addition, the $\mathrm{pH}$ values of violet-blue and purple Phalaenopsis flowers ranged from 5.33 to 5.54 and 4.77 to 5.04 , respectively. Furthermore, the molar ratio of metal ions (including $\mathrm{Al}^{3+}, \mathrm{Ca}^{2+}$ and $\mathrm{Fe}^{3+}$ ) to anthocyanin in violet-blue color Phalaenopsis was 190-, 49-, and 51-fold higher, respectively, than those in purple-color Phalaenopsis.

Conclusion: Cyanidin-based anthocyanin was detected in violet-blue color Phalaenopsis and was concomitant with a high $\mathrm{pH}$ value and high molar ratio of $\mathrm{Al}^{3+}, \mathrm{Ca}^{2+}$ and $\mathrm{Fe}^{3+}$ to anthocyanin content. Enhanced expression of delphinidin is needed to produce true-blue Phalaenopsis.
\end{abstract}

Keywords: Delphinidin, DgF3'5'H, Metal ions, Orchids, PeF3'H, pH, PhF3'5'H, Phalaenopsis, Violet-blue

\section{Background}

Phalaenopsis hybrids are among the most popular orchids in flower markets because of their long-lived and spectacular flowers. One of the special agronomic traits for Phalaenopsis is their abundant flower color, including

\footnotetext{
*Correspondence: winter60606@gmail.com; hhchen@mail.ncku.edu.tw 'Department of Life Sciences, National Cheng Kung University, Tainan 701, Taiwan

Full list of author information is available at the end of the article
}

white, yellow and red-purple. For the red-purple series, the flower colors range from red-purple, purple, purpleviolet, violet and violet-blue (Additional file 1) according to the Royal Horticultural Society Color Chart (RHSCC). In Taiwan, red-purple flowers are the most popular because of the color's association with happiness. However, violet-blue Phalaenopsis flowers are rarely seen in orchid markets mainly because of the difficulty in breeding bluecolor flowers, few native species with blue flowers, short-

(c) The Author(s). 2020 Open Access This article is licensed under a Creative Commons Attribution 4.0 International License, which permits use, sharing, adaptation, distribution and reproduction in any medium or format, as long as you give appropriate credit to the original author(s) and the source, provide a link to the Creative Commons licence, and indicate if changes were made. The images or other third party material in this article are included in the article's Creative Commons licence, unless indicated otherwise in a credit line to the material. If material is not included in the article's Creative Commons licence and your intended use is not permitted by statutory regulation or exceeds the permitted use, you will need to obtain permission directly from the copyright holder. To view a copy of this licence, visit http://creativecommons.org/licenses/by/4.0/ The Creative Commons Public Domain Dedication waiver (http://creativecommons.org/publicdomain/zero/1.0/) applies to the data made available in this article, unless otherwise stated in a credit line to the data. 
lived flowers, small flower size, and easy color fading (Additional file 2). The earliest breeding of a blue flower cultivar of Phalaenopsis, recorded by the RHSCC, was named $P$. Kenneth Schubert, in 1963. After years of breeding, Phalaenopsis still lacks a true-blue color flower, and violet-blue is the bluest color in Phalaenopsis flowers. Hence, to breed a Phalaenopsis flower with blue color in addition to other stamen horticultural traits is desired and highly expected from both orchid breeders and consumers.

Flower colors are important for plants to be able to attract their pollinators. Blue is a beautiful and attractive color in flowers. However, there are few wild plants with blue flowers as compared with those with red flowers possibly because of the co-evolution of flower color and visual capture of their pollinators [1].

The three major classes of plant pigments involve the distinct chemical structures of betalains, carotenoids and anthocyanins [2]. Anthocyanin, one class of flavonoids soluble in water, is synthesized in the cytosol and localized in vacuoles. Seven core structural genes are well known to encode enzymes that catalyze the biosynthesis of anthocyanins [3]. In the biosynthesis of flavonoid and anthocyanin pigments, chalcone synthase is the first step that catalyzes sequential condensations with three acetate units from malonyl-CoA and $\rho$-coumaroyl-CoA. The result is naringenin chalcone $\left(2^{\prime}, 4,4^{\prime}, 6^{\prime}\right.$-tetrahydroxychalcone) and $6^{\prime}$-deoxychalcon $\left(2^{\prime}, 4,4^{\prime}\right.$-trihydroxychalcone) which are then catalyzed by chalcone isomerase via stereospecific cyclization to form naringenin $(\mathrm{N})$ and liquiritigenin, respectively. Flavanone-3-hydroxylase $(\mathrm{F} 3 \mathrm{H})$ converts the flavonones (naringenin and eriodictyol) to dihydroflavonols (dihydrokaempferol [DHK]). Flavonoid-3' - hydroxylase (F3'H) and flavonoid-3',5'hydroxylase $\left(\mathrm{F}^{\prime} \mathrm{5}^{\prime} \mathrm{H}\right)$ are functional flavonoid B-ring hydroxylation and are required for biosynthesis of flavones, flavanones, flavonols and anthocyanins. With anthocyanins, F3' $\mathrm{H}$ is needed for the formation of cyanidins and F3' 5 ' $\mathrm{H}$ for the formation of delphinidins for red and blue colors, respectively. Both F3'H and F3'5' $\mathrm{H}$ compete for the common precursors of $\mathrm{N}$ and DHK. Dihydroflavonol-4-reductase (DFR) reduces dihydroflavonols (DHK, dihydroquercetin and dihydromyricetin) to leucoanthocyanidins (leucopelargonidin, leucocyanidin and leucodelphinidin). Anthocyanidin synthase (ANS) is involved in a crucial step of anthocyanin formation because it catalyzes the oxidation of colorless leucoanthocyanidin to the precursor of anthocyanidins. Glycosylation of a hydroxyl group at the $\mathrm{C}-3$ position of anthocyanidins is the primary modification step needed to stabilize anthocyanins and is required for further modifications. UDP-glucose: flavonoid-3-0-glucosyl transferase (3GT) glycosylates anthocyanidins and flavonols on the 3 position to produce anthocyanins [4].
Previous studies showed many commercial horticultural plants without blue hue flowers due to lack of F3'5'H. Molecular approaches have been used to create blue-color flowers in rose [5], carnation [6,7] and chrysanthemum by ectopic overexpression of F3'5' $\mathrm{H}[8,9]$. Chrysanthemums (Chrysanthemum morifolium Ramat.) without blue-, violet- or purple-flowered cultivars are due to the absence of the F3'5' $\mathrm{H}$ gene that encodes the key enzyme for delphinidin-based anthocyanin biosynthesis [9]. The flower colors of transgenic plants with heterologous F3'5' $\mathrm{H}$ overexpression produce delphinidin-based anthocyanins and change from a red-purple to a purple-violet hue [9]. Thus, F3'5'H may compete with F3' $\mathrm{H}$ for their common substrates, to lead to the production of dephinidin. Regulation of $\mathrm{F}^{\prime} 5^{\prime} \mathrm{H}$ gene expression in the delphinidin-based anthocyanin biosynthesis pathway could be a successful strategy for high production of delphinidin-based anthocyanins and blue hue in Phalaenopsis flowers.

Different levels of vacuolar $\mathrm{pH}$ could cause a color shift in flowers with the same anthocyanin compounds. Flowers with the same anthocyanin compounds can have a color change with diverse levels of vacuolar $\mathrm{pH}$. For example, an increase in $\mathrm{pH}$ from 6.6 to 7.7 due to the polyacylation of peonidin glycoside cause blue coloration in the corolla of morning glory [10]. In addition, both InNHX1 and InNHX2 translate proteins responsible for transporting $\mathrm{K}^{+} / \mathrm{Na}^{+}$into the vacuoles in morning glory, and produce weakly alkaline vacuoles at the flowering stage [11-13]. $\mathrm{Na}^{+}\left(\mathrm{K}^{+}\right) / \mathrm{H}^{+}$exchanger (NHX) drives a vacuolar $\mathrm{pH}$ increase during flower opening, causing a color shift from red to blue [11]. In both mutants of Vtype ATPase, ph 5 and $p h 1$, vacuolar acidification was reduced and caused purple-colored petunia [14, 15]. Blue color development of metalloanthocyanins obtained from different blue flower petals has been found. $\mathrm{Mg}^{2+}$ and $\mathrm{Fe}^{3+}$ are essential for blue coloration in blue poppy flower $[16,17] . \mathrm{Fe}^{3+}$ and $\mathrm{Al}^{3+}$ may affect blue coloration in the blue cornflower Centaurea cyanus [18]. The molar ratio of vacuolar metal ions, flavones and anthocyanin is 2:6:6 and forms a supermolecular complex, with metalloanthocyanin acting as a conclusive factor, causing blue blooms [16]. Therefore, the content of specific metal ions is a crucial factor influencing blue coloration in flowers.

The R2R3-MYB transcription factors are crucial in influence on the spatial and temporal patterning of anthocyanins in many flowers [19-21]. In Phalaenopsis, three PeMYBs, including PeMYB2, PeMYB11, and PeMYB12 involve in the different pigmentation patterning of fullred pigmentation, red spots, and venation, respectively [22]. Transient overexpression of PeMYB2 in whitecolor Phalaenopsis flower, which has little or no expression of PeMYB2, causes red pigmentation and 
anthocyanin accumulation and stimulate the expression of downstream structural genes, $P e F 3 H, P e D F R$, and PeANS [22].

Here, we aimed to study the mechanisms in the formation of violet-blue color in Phalaenopsis flower. In addition, we tested the initial assumption framework on converting the white-color orchids to blue hue by transient overexpression of PeMYB2 and heterologous $F 3^{\prime} 5^{\prime} \mathrm{H}$ as well as knockdown of endogenous $F 3^{\prime} H$ in Phalaenopsis by using virus-induced gene silencing (VIGS) to access whether delphinidin could accumulate. This study will set the groundwork for molecular breeding of Phalaenopsis cultivars with novel blue color pigmentation.

\section{Results}

\section{Cyanidin-based anthocyanin is highly accumulated in} Phalaenopsis spp. of various colors

To examine whether anthocyanins differentially accumulated in Phalaenopsis, anthocyanins were extracted and analyzed by using HPLC. Pure compounds of both cyanidin and delphinidin were used as standards (Fig. 1). Cyanidin was the major and only anthocyanin compound detected in Phalaenopsis of different colors (Fig. 1a-g), including purple P. OX Honey 'OX1372', purple-violet $P$. Big Chili, dark purple Phal. OX Firebird 'OX1506 mutant', violet-blue Phal. Kenneth Schubert, violet-blue $P$. tau Chiang Sapphire, violet $P$. (Germaine Vincent $\mathrm{x}$ Samera 'indigo') 'S304' and violet-blue $P$. Purple Martin, whereas delphinidin was highly detected in blue-color Delphinium grandiflorum (Fig. 1h). These results suggest that all Phalaenopsis cultivars have cyanidin-based anthocyanin even though they have various colors, so we further examined factors affecting the violet-blue color of Phalaenopsis cultivars.

\section{Strong expression of PeF3'H was concomitant with cyanidin-based anthocyanin expression in various Phalaenopsis spp.}

To study the differential gene expression of $F 3^{\prime} H$ and F3'5'H in Phalaenopsis, PeF3'H was isolated from OrchidBase $[23,24]$ and $P h F 3 ' 5 ' H$ was amplified from purplecolor $P$. Purple Martin by using $5^{\prime}-$ and $3{ }^{\prime}$-RACE. We performed phylogenetic analysis with $P e F 3^{\prime} H$ and $P h F 3^{\prime} 5^{\prime} H$ and 12 flavanone hydroxylases from other plants (Fig. 2). PeF3'H clustered with the cytochrome 75B group and PhF3'5' $H$ with the cytochrome 75A group. The expression of PeF3' $H$ and $P h F 3^{\prime} 5^{\prime} H$ in sepals and petals of floral buds from among various Phalaenopsis cultivars was examined by quantitative RT-PCR (qRT-PCR) (Fig. 3). PeF3'H level was higher than $P h F 3^{\prime} 5^{\prime} H$ level in red-purple and purple cultivars and also violet and violet-blue cultivars. In contrast, $P e F 3^{\prime} H$ and $P h F 3$ '5' $H$ levels were low in white-color $P$. aphrodite and white-petals/red-lip $P$. OX Brother Seamate
'OX1313' (Fig. 3). This result indicates an association between the strong expression of $P e F 3$ ' $H$ and high accumulation of cyanidin-based anthocyanin in all Phalaenopsis cultivars.

\section{Accumulation of delphinidin-based anthocyanin and blue pigmentation formation resulted from ectopic overexpression of both $\mathrm{DgF3}^{\prime} \mathrm{5}^{\prime} \mathrm{H}$ and PeMYB2}

To assess whether delphinidin could be accumulated in Phalaenopsis orchids, we used ectopic overexpression of $F 3^{\prime} 5^{\prime} \mathrm{H}$. First, we confirmed whether PhF3'5' $\mathrm{H}$ from Phalaenopsis orchids has any enzyme activities. Agrobacterium tumefaciens containing $P h F 3$ '5' $H$ was infiltrated into white tepals of $P$. Sogo Yukidian 'V3' (abbreviated as V3 hereafter) (Fig. 4a). We previously showed that transient overexpression of PeMYB2 could increase the expression of downstream structural genes of $\mathrm{PeF} 3 \mathrm{H}$, PeDFR and PeANS and resulted in anthocyanin accumulation [22]. Overexpression of PeMYB2 in white-color V3 resulted in $1.2 \%$ delphinidin and $98.8 \%$ cyanidin accumulation with a red-purple color (Fig. 4b). Overexpression of $P h F 3{ }^{\prime}{ }^{\prime} H$ and PeMYB2 resulted in 1.6\% delphinidin and $98.4 \%$ red-purple cyanidin, which suggests that PhF3'5' $H$ has no enzyme activity and no delphinidin accumulation resulted (Fig. 4c). In contrast, overexpression of both $D g F 3^{\prime} 5^{\prime} H$ (from $D$. grandiflorum) and PeMYB2 resulted in 53.6\% delphinidin and 46.4\% cyanidin accumulation (Fig. 4d). These results suggest that a blue flower can result from functional $F 3^{\prime} 5^{\prime} H$ present in Phalaenopsis and the activation of F3H, DFR, and ANS by PeMYB2.

\section{Substrate recognition site 6 (SRS6) of PeF3'H and $\mathrm{PhF}^{\prime} \mathrm{S}^{\prime} \mathrm{H}$ and prediction of substrate docking} There are six substrate recognition sites (SRSs) near the heme group of $\mathrm{F}^{\prime} 5^{\prime} \mathrm{H}$; mutation of the individual amino acids at these sites might influence enzyme function [25-27].

To examine why PhF3'5'H cannot produce delphinidin, we wondered about divergence in amino acids in its sequences. The deduced amino acid sequences of PhF3'5' $H$ were analyzed. They contained three conserved regions including an AGTDTS cytochrome P450 conversed region, EXXR oxygen binding motif and FGAGRRICAG heme binding domain (Fig. 5a). The amino acid sequences of SRS1, SRS2, SRS4, SRS5 and SRS6 domains in PhF3'5' $\mathrm{H}$ and $\mathrm{DgF3}^{\prime} 5^{\prime} \mathrm{H}$ are in Fig. 5a.

$\mathrm{M}[\mathrm{D} / \mathrm{E}] \mathrm{Ex}[\mathrm{F} / \mathrm{Y}] \mathrm{Gx}[\mathrm{T} / \mathrm{S} / \mathrm{A}] \mathrm{xQ}$ is the conserved region of SRS6, and position 8 of SRS6 is the crucial amino acid that determines functional divergence between F3'H and F3'5'H [26, 27]. Both PeF3'Hs of Phalaenopsis orchids have a threonine $(\mathrm{T})$ residue at position 8 of SRS6, isolated from $P$. Purple Martin and $P$. hybrid 'King Car' (Fig. 5b). In contrast, all F3'5'Hs of Phalaenopsis orchids have a valine $(\mathrm{V})$ residue at position 8 of 

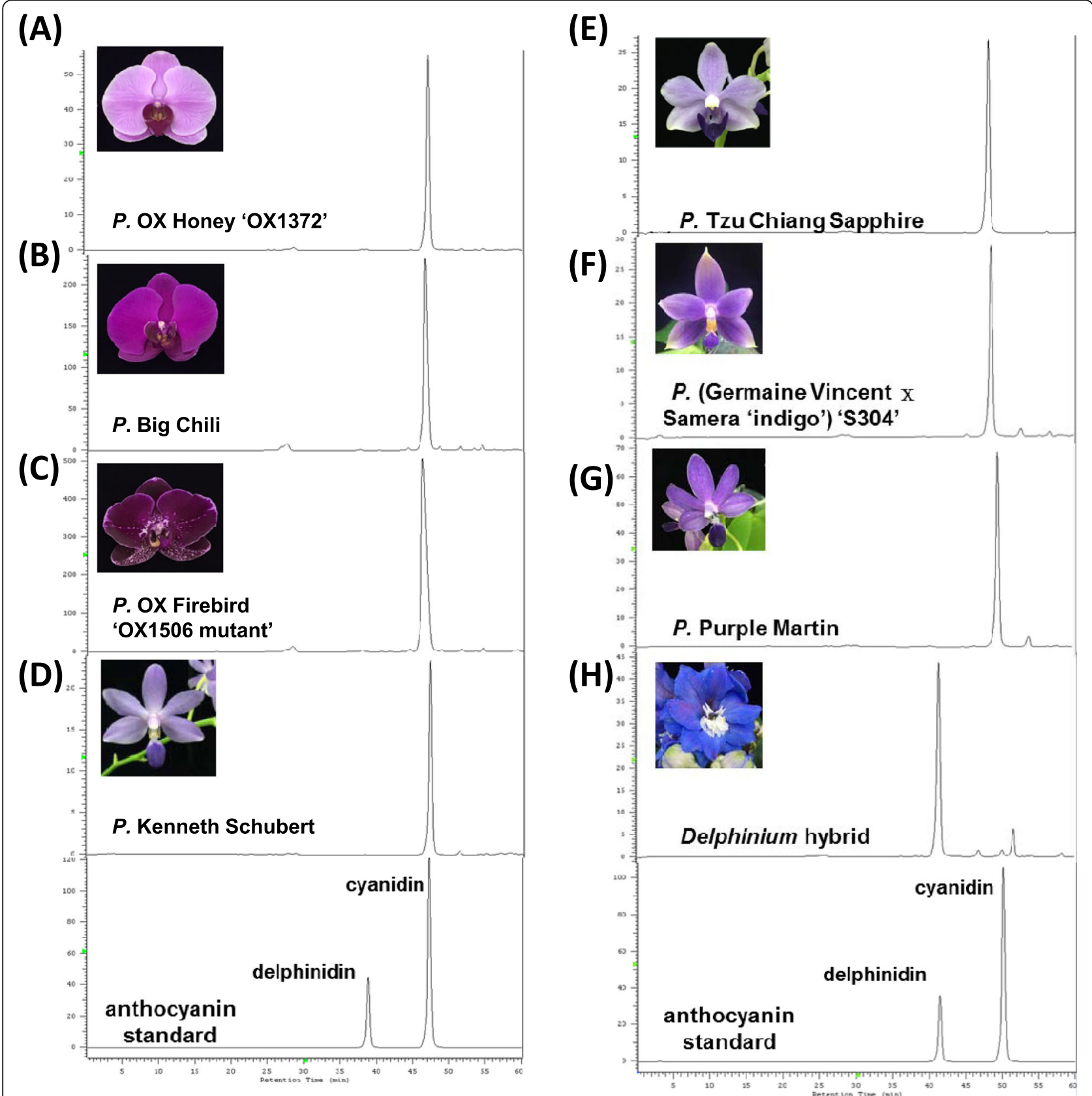

Fig. $1 \mathrm{HPLC}$ analysis of anthocyanin compound. Various flower colors of Phalaenopsis were used to determine the types of anthocyanin in various flower colors of Phalaenopsis, including (a) P. OX Honey 'OX1372', (b) P. Big Chile, (c) P. OX Firebird 'OX1506 mutant', (d) P. Kenneth Schubert, (e) P. Tzu Chiang Sapphire, (f) P. (Germaine Vincent x Samera 'indigo') 'S304', (g) P. Purple Martin, and (h) Delphinium hybrid. Delphinium was included as a control group. Anthocyanin compounds of delphinidin and cyanidin were also included to show the peaks of standards

SRS6, isolated from $P$. aphrodite, P. equestris, P. bellina, P. schilleriana, P. lueddemanniana, P. Purple Martin and P. violacea 'Indigo Blue' (Fig. 5b). In addition, F3'5' Hs of other genera in Orchidaceae also have a V at position 8 of SRS6, including Dendrobium hybrid, Cymbidium ensifolium, Orchis italic, Gastrodia elata and Vanilla planifolia (Fig. 5b). One allele of $\mathrm{F3}^{\prime} \mathrm{S}^{\prime} \mathrm{H}$ from $\mathrm{V}$. planifolia has an alanine (A) at position 8 of SRS6 (Fig. 5b).
In addition, F3'5'Hs have two prolines $(\mathrm{P})$ at positions 5 and 10 of SRS6 in Orchidaceae (Fig. 5b). In contrast, both phenylalanine $(\mathrm{F})$ and glutamine $(\mathrm{Q})$ are at positions 5 and 10 of SRS6 for D. grandiflorum.

The substrate binding sites for N, DHQ and eriodictyol (E) on $\mathrm{PhF3}^{\prime} 5^{\prime} \mathrm{H}$ and $\mathrm{DgF3}{ }^{\prime} 5^{\prime} \mathrm{H}$ were predicted by using SwissDock. Of the approximately 30 different conformations obtained in the substrate docking prediction 

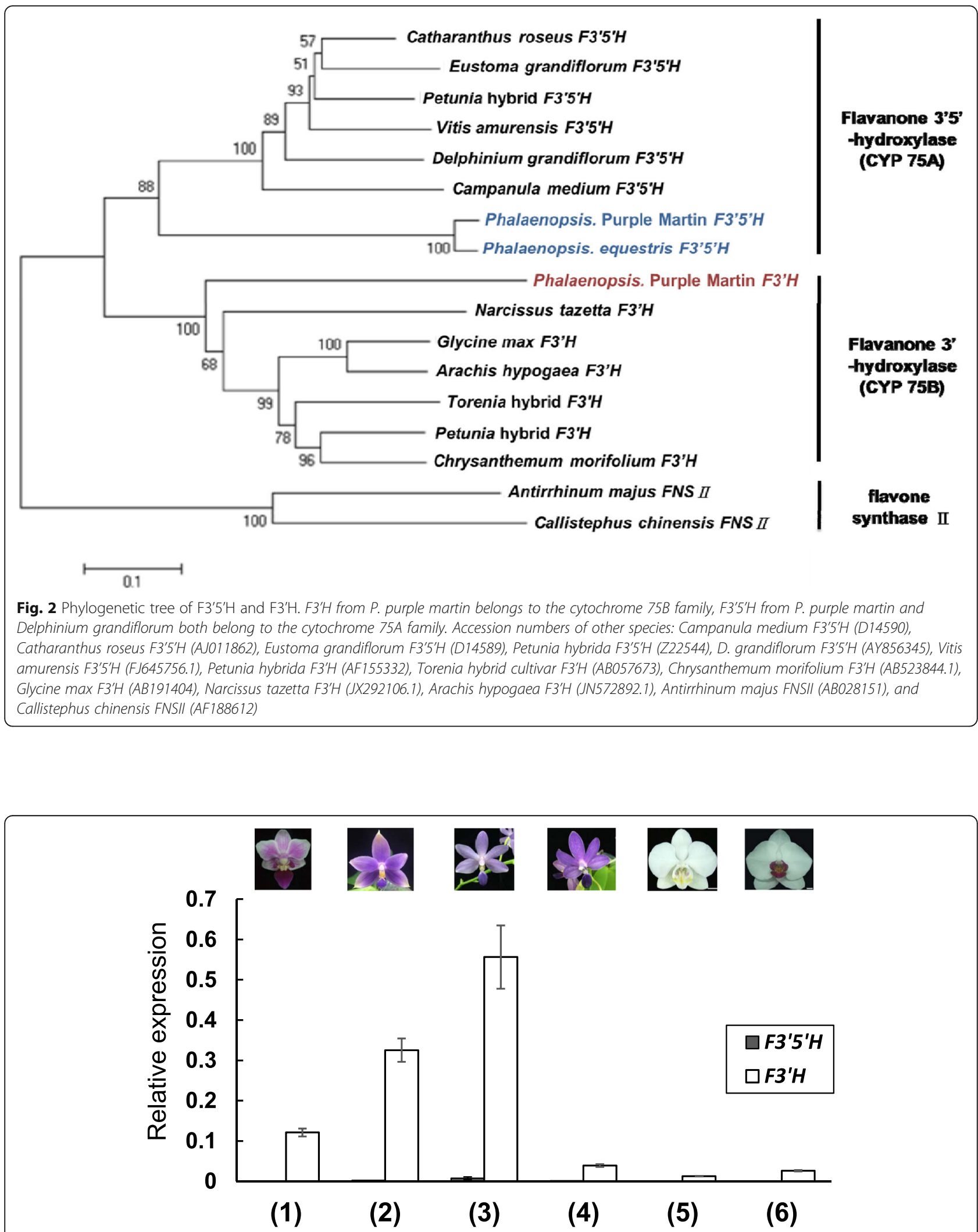

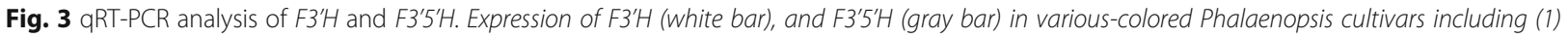
P. hybrid 'King Car' (2) P. (Germaine Vincent x Samera 'Indigo') 'S304', (3) P. Kenneth Schubert, (4) P. Purple Martin, (5) P. aphrodite, and (6) P. OX Brother Seamate 'OX1313' 


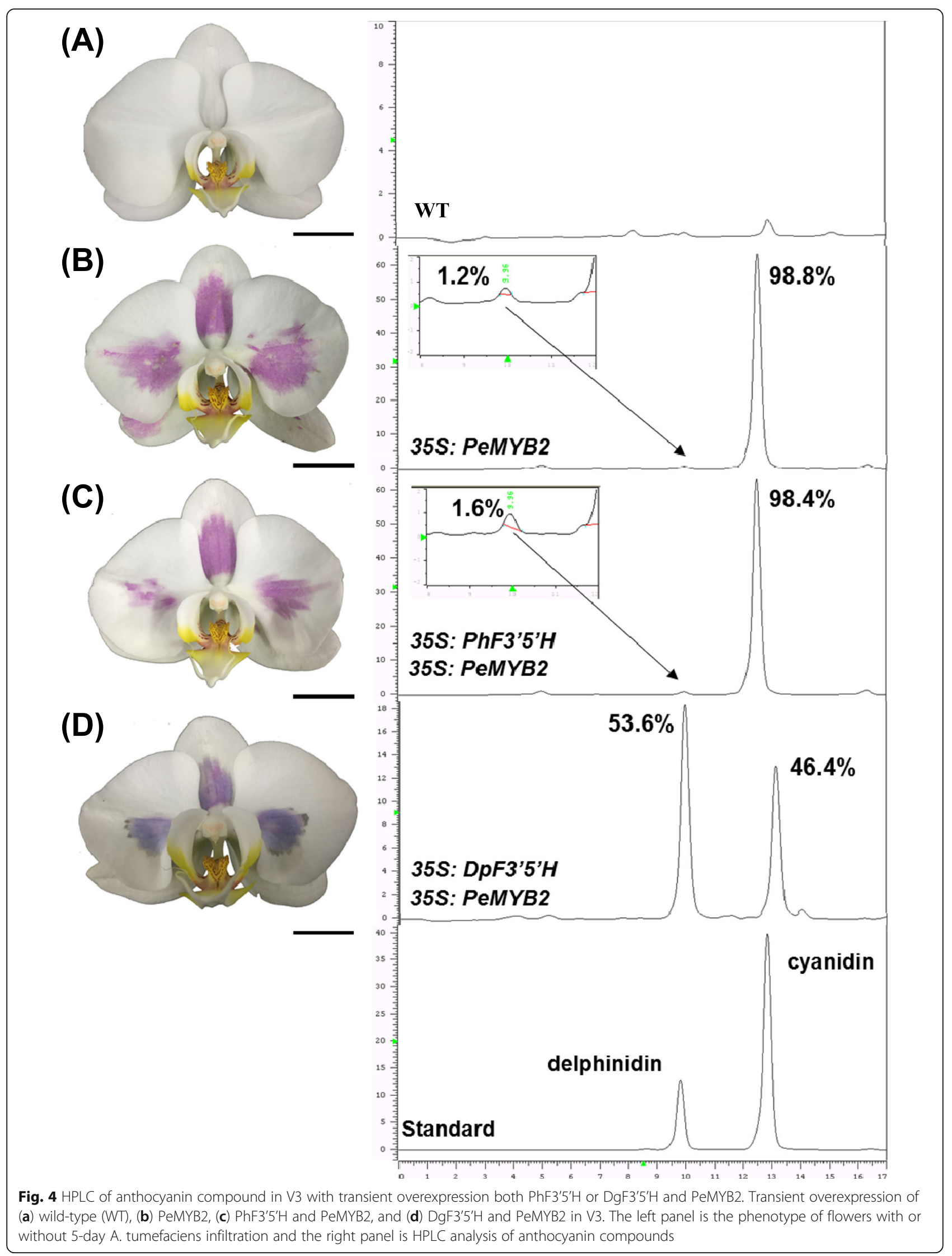


(A)

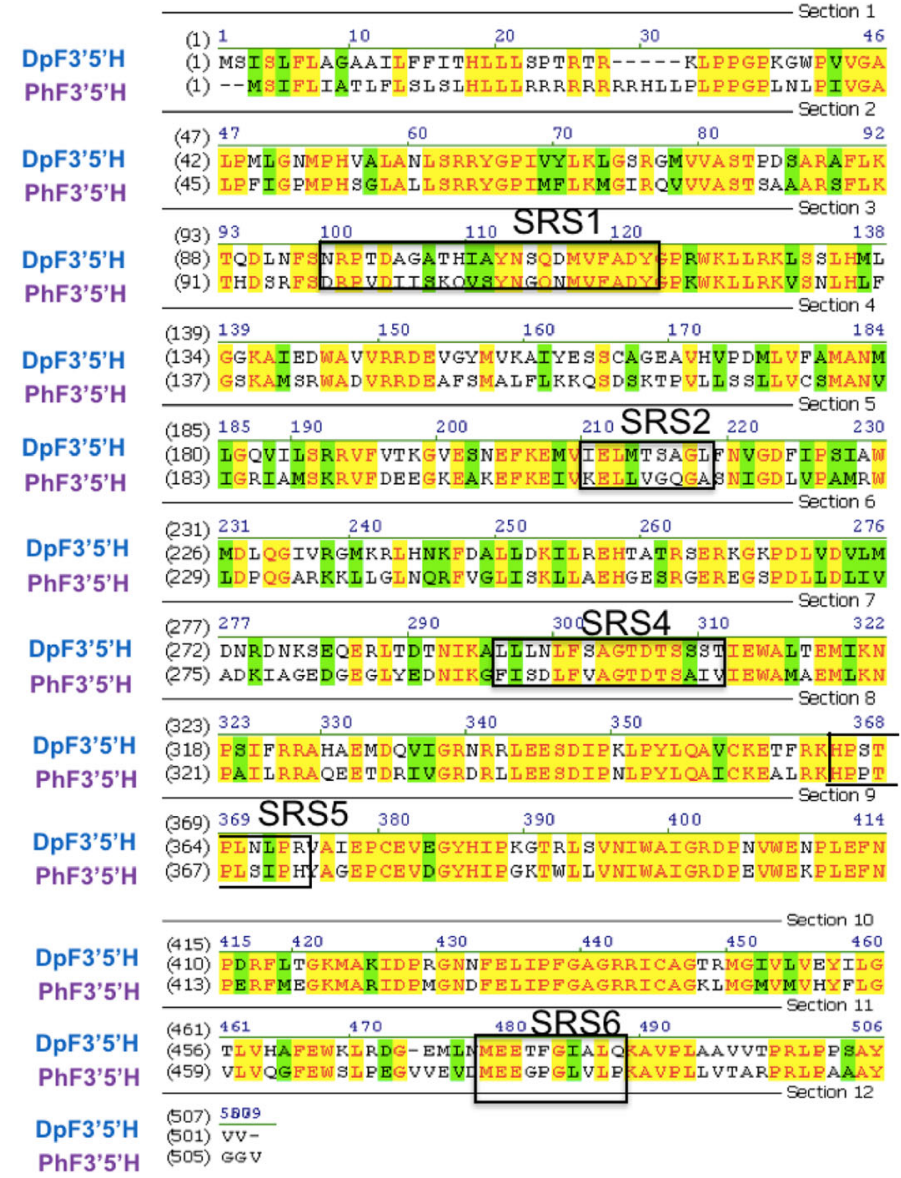

(B)

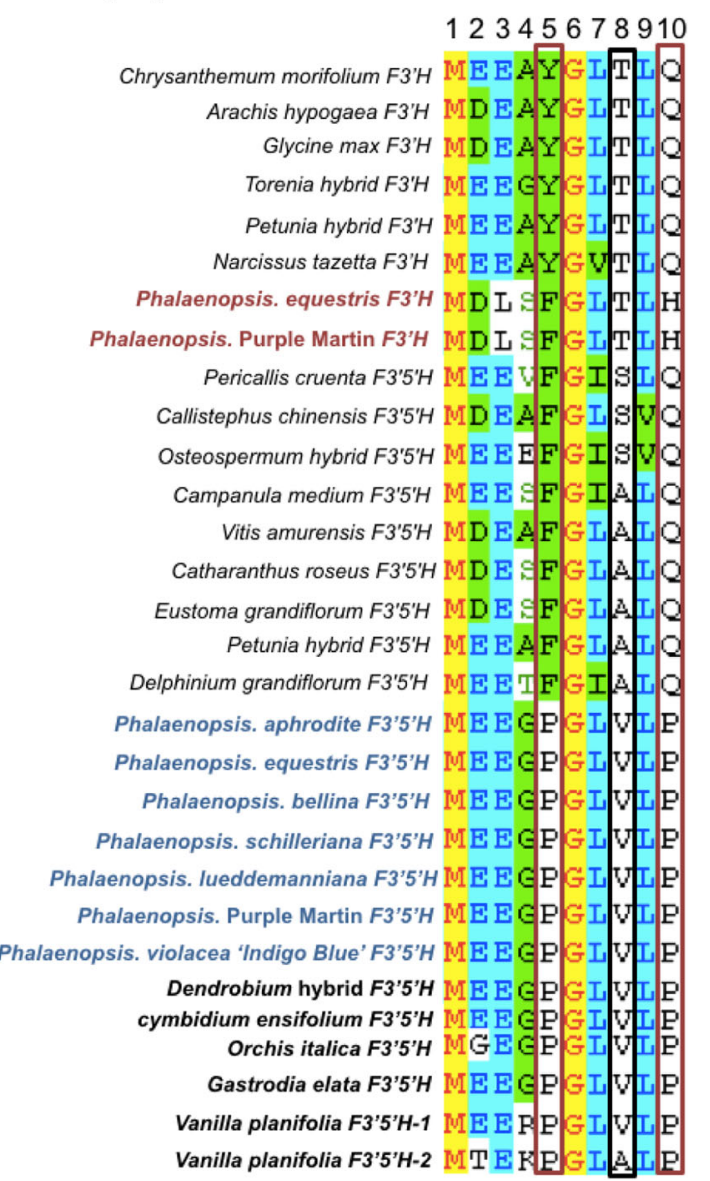

Fig. 5 Multiple alignment of substrate recognition site 6 (SRS6) with F3'Hs and F3'5'Hs. a SRS1, SRS2, SRS4, SRS5 and SRS6 are boxed. b Multiple alignment analysis of $\mathrm{F}^{\prime} \mathrm{Hs}$ and $\mathrm{F}^{\prime} 5^{\prime} \mathrm{Hs}$ from Phalaenopsis (highlighted in red and blue, respectively) and other members of Orchidaceae including Dendrobium, Cymbidium, Orchis, Gastrodia and Vanilla (highlight in deep dark). Positions 5 and 10 of SRS6 amino acids are shown in red squares, and position 8 of SRS6 is shown in a black box. Accession numbers of other plants: Campanula medium F3'5'H (D14590), Catharanthus roseus F3'5'H (AJ011862), Pericallis cruenta F3'5'H (DQ257626.1), Callistephus chinensis F3'5'H (AAG49299.1), Osteospermum hybrid F3'5'H (DQ257627.1), Eustoma grandiflorum F3'5'H (D14589), Petunia hybrida F3'5'H (Z22544), Delphinium grandiflorum F3'5'H (AY856345), Vitis amurensis F3'5'H (FJ645756.1), Petunia hybrida F3'H (AF155332), Torenia hybrid cultivar F3'H (AB057673), Chrysanthemum morifolium F3'H (AB523844.1), Glycine max F3'H (AB191404), Narcissus tazetta F3'H (JX292106.1), Arachis hypogaea F3'H (JN572892.1)

with N, DHQ and E, the lowest energy conformation was selected as the most probable binding model. Prediction results showed that the aromatic rings (B-ring) of $\mathrm{N}, \mathrm{DHQ}$ and $\mathrm{E}$ were oriented toward the $\mathrm{N}$-terminal of SRS4 and SRS1 of PhF3'5'H (Fig. 6d-f). In contrast, the aromatic rings (B-ring) of N, DHQ and E were oriented toward the C-terminal of SRS4, SRS5 and SRS6 of DgF3'5'H (Fig. 6a-c).

\section{Violet-blue cultivars have higher vacuolar $\mathrm{pH}$ than do purple and white cultivars}

To understand any divergent $\mathrm{H}^{+}$concentrations among various-colored Phalaenopsis, the $\mathrm{pH}$ value was measured from flower extracts (Fig. 7). The $\mathrm{pH}$ values showed an increasing trend as Phalaenopsis flower colors became more violet blue (Fig. 7). Phalaenopsis cultivars with violet and violet-blue flowers had higher $\mathrm{pH}$ values than those with red-purple, purple and white flowers. Cultivars in the purple group, $P$. OX Firebird 'OX1506 mutant' and P. OX Honey 'OX1372', had pH values of 4.77 and 4.85 , respectively (Fig. 7). The $\mathrm{pH}$ value of purple-violet $P$. Big Chili was 5.04 (Fig. 7). Cultivars in the violet group, $P$. violacea 'Indigo blue' and $P$. (Kenneth Schubert x Samera) 'KS1226', had pH values of 5.52 and 5.54, respectively (Fig. 7). Cultivars in the violet-blue group, $P$. Purple Martin and $P$. Kenneth Schubert, had $\mathrm{pH}$ values of 5.33 and 5.50, respectively (Fig. 7). Cultivars in the white group, $P$. aphrodite and 


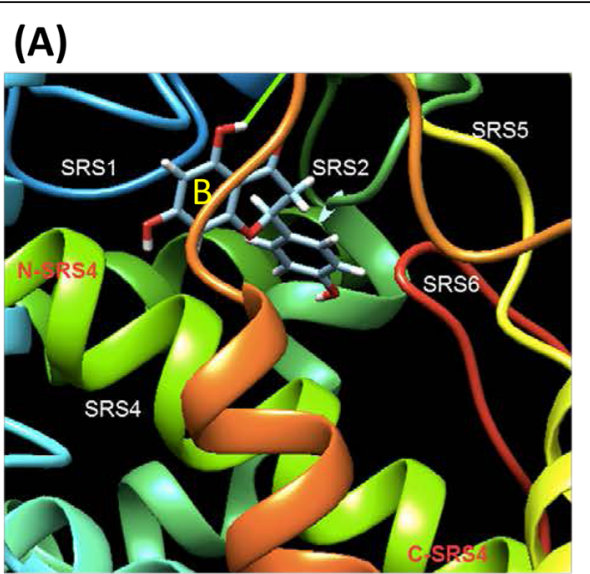

(B)

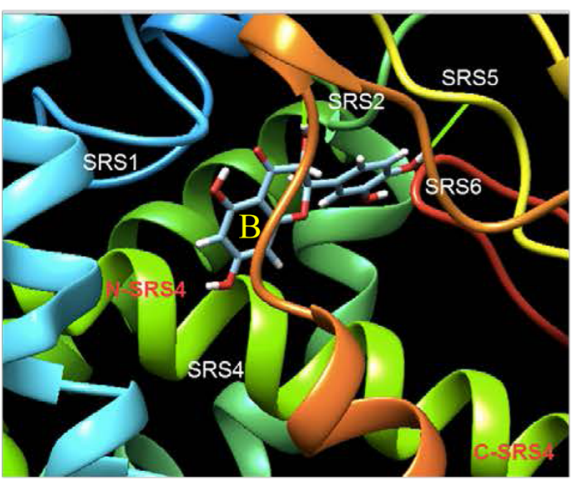

(C)

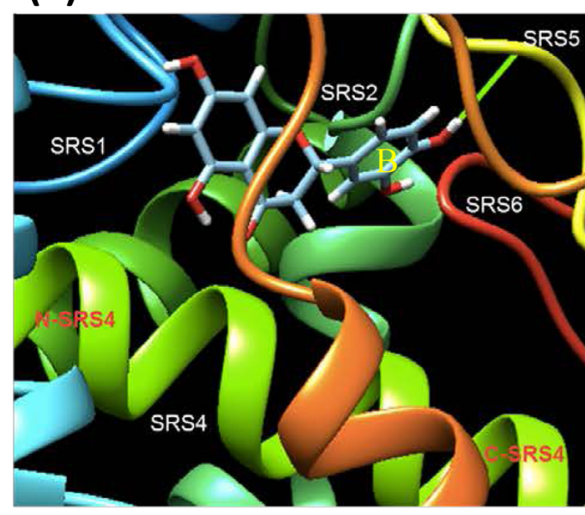

(D)

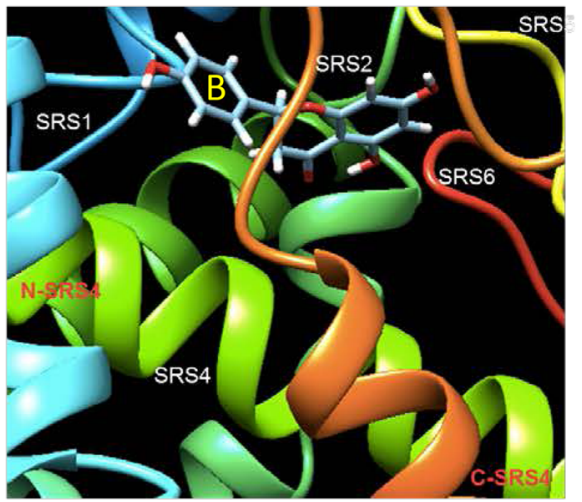

(E)

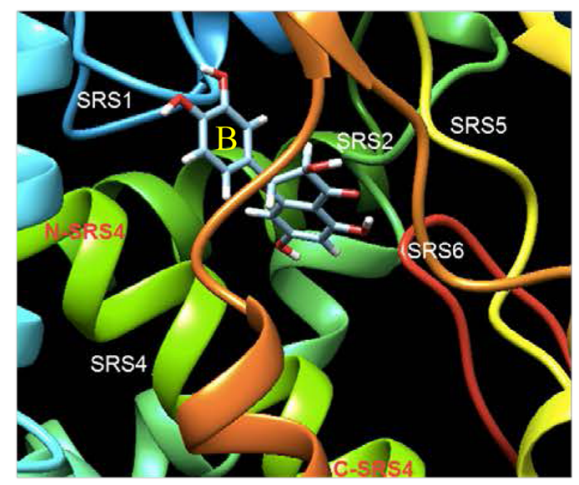

(F)

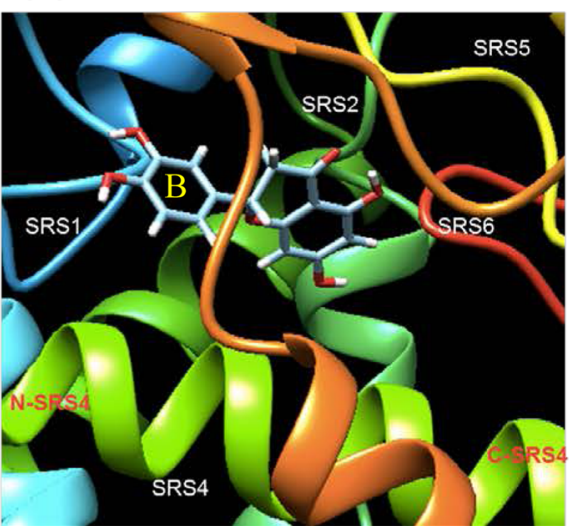

Fig. 6 Substrate docking of F3'5'H and its substrates. Substrate docking prediction of DgF3'5'H ( $(\boldsymbol{a} \sim \boldsymbol{c})$ and PhF3'5'H (d $\sim \boldsymbol{f})$. The substrates used for docking are naringenin ( $\boldsymbol{a}$ and $\boldsymbol{d})$, dihydroquercetin ( $\boldsymbol{b}$ and $\boldsymbol{e}$ ), and eriodictyol (c and $\boldsymbol{f}$ ). The B-ring is labeled as " $B$ " (a-f)

V3, had pH values of 5.05 and 5.13, respectively (Fig. 7). These results suggest that decreased acidification enables the presentation of blue hues of Phalaenopsis orchids.

\section{Absorption spectra of anthocyanin extracts from} Phalaenopsis orchids

To confirm whether anthocyanins under various levels of acidification will present different colors, anthocyanins were extracted from purple-violet $P$. Big Chili
(Fig. 8a) and added into buffers adjusted to various $\mathrm{pH}$ values from 2.9 to 6.8 (Fig. 8b). The anthocyanins shifted toward a red hue in the acidic conditions and blue hue in basic conditions (Fig. 8b). In the absorption spectra of visible light, the red-shift of the wavelength occurred under basic conditions (Fig. 8c). In addition, anthocyanins were easily degraded in the alkaline solution (Fig. 8d). This result suggests that Phalaenopsis anthocyanins present a blue color in basic environments and are 


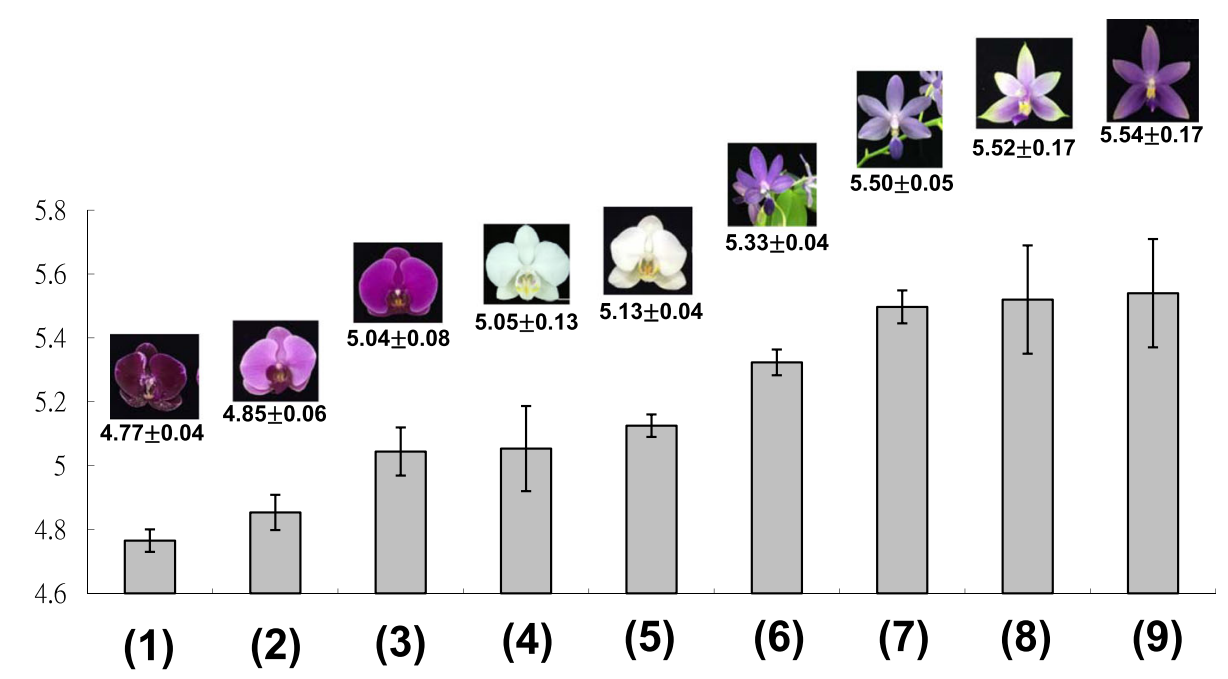

Fig. $7 \mathrm{pH}$ value in petal crude extracts of various-colored cultivars of Phalaenopsis. (1) P. OX Firebird 'OX1506 mutant', (2) P. OX Honey 'OX1372', (3) P. Big Chili, (4) P. Sogo Yukidian 'V3', (5) P. aphrodite subsp. formosana, (6) P. Purple Martin, (7) P. Kenneth Schubert, (8) P. violacea 'Indigo blue', and (9) P. violacea 'KS1266'

unstable in alkaline conditions with high pH values (Fig. 8d). In fact, the flower color faded easily among consecutive flowers in the same inflorescence of violet-blue Phalaenopsis cultivars (Additional file 2). The newly bloomed flower was purple, and it became a light purple color as the flowers faded (Additional file 2). The correlation between $\mathrm{pH}$ value and violet blue color formation was highly positive, as analyzed by Pearson's correlation coefficient $\left(R^{2}=0.895\right)$.

\section{Positive association between increased concentration of metal ions and violet-blue color formation}

We then compared the ratio of metal ions to anthocyanin between purple and violet-blue Phalaenopsis cultivars. Five metal ions including $\mathrm{Mg}^{2+}, \mathrm{Al}^{3+}, \mathrm{Ca}^{2+}, \mathrm{Fe}^{3+}$ and $\mathrm{Zn}^{2+}$ were analyzed in the purple color cultivar $P$. OX Honey 'OX1372', violet-blue color cultivar P. Kenneth Schubert, and dark-purple colored $P$. OX Firebird 'OX1506 mutant' by using ICP-MS (Table 1). The concentrations of cyanidin were $0.68,0.26$, and $10.74 \mu \mathrm{mol}$ in purple Phal. OX Honey 'OX1372', violet-blue $P$. Kenneth Schubert, and dark-purple P. OX Firebird 'OX1506 mutant', respectively.

The molar ratios of $\mathrm{Al}^{3+}, \mathrm{Ca}^{2+}$ and $\mathrm{Fe}^{3+}$ to cyanidin were 190-, 49-, and 51-fold higher, respectively, in violet-blue $P$. Kenneth Schubert than in dark-purple $P$. OX Firebird 'OX1506 mutant' (Table 1). In contrast, the molar ratios of $\mathrm{Mg}^{2+}$ and $\mathrm{Zn}^{2+}$ to cyanidin did not differ between violet-blue $P$. Kenneth Schubert and purple $P$. OX Honey 'OX1372'. These results indicate divergence in molar ratios of $\mathrm{Al}^{3+}, \mathrm{Ca}^{2+}$ and $\mathrm{Fe}^{3+}$ to cyanidin-based anthocyanin between purple and violet-blue Phalaenopsis. Association between the molar ratios of metal ion to cyanidin and violet blue color formation was analyzed statistically by Pearson's correlation coefficient. The positive correlation between the molar ratios of $\mathrm{Al}^{3+}$, $\mathrm{Ca}^{2+}$ and $\mathrm{Fe}^{3+}$ to cyanidin and violet blue color formation was high $\left(R^{2}=0.94,0.88\right.$ and 0.91 , respectively), whereas that between the molar ratios of $\mathrm{Mg}^{2+}$ and $\mathrm{Zn}^{2+}$ to cyanidin and blue color formation was low $\left(R^{2}=0.5\right.$ and 0.15 , respectively).

\section{Discussion}

Same anthocyanin compound but different vacuolar $\mathrm{pH}$ values between violet-blue and purple-red flowers

Vacuolar $\mathrm{pH}$ is higher in blue flowers than red flowers in petunia, morning glory and hydrangea, but blue and red flowers have the same anthocyanin compound [10, 14, 28]. This indicates that vacuolar $\mathrm{pH}$ is a significant factor regulating flower color among red to blue colors when observing different colored flowers with the same anthocyanin compound accumulated. In Phalaenopsis orchids, cyanidinbased anthocyanin was highly accumulated in flowers from red-purple to violet-blue. However, violet-blue Phalaenopsis cultivars have higher $\mathrm{pH}$ in flower sap than do purple cultivars.

Color-shift from violet-blue to purple might be regulated by the divergence of molar ratio of metal ions to cyanidin-based anthocyanin in Phalaenopsis

Previous studies showed that blue-red bicolor tulips had a molar ratio of $\mathrm{Fe}^{3+}$ to delphinidin-based anthocyanin 39-fold higher in blue than red cells [29]. In blue and red hydrangea flowers, the molar ratio of $\mathrm{Al}^{3+}$ to delphinidin-based anthocyanin was 40-fold higher in blue than red flowers [30]. In blue and purple cornflowers, the molar ratio of $\mathrm{Fe}^{3+}$ to cyanidin-based 


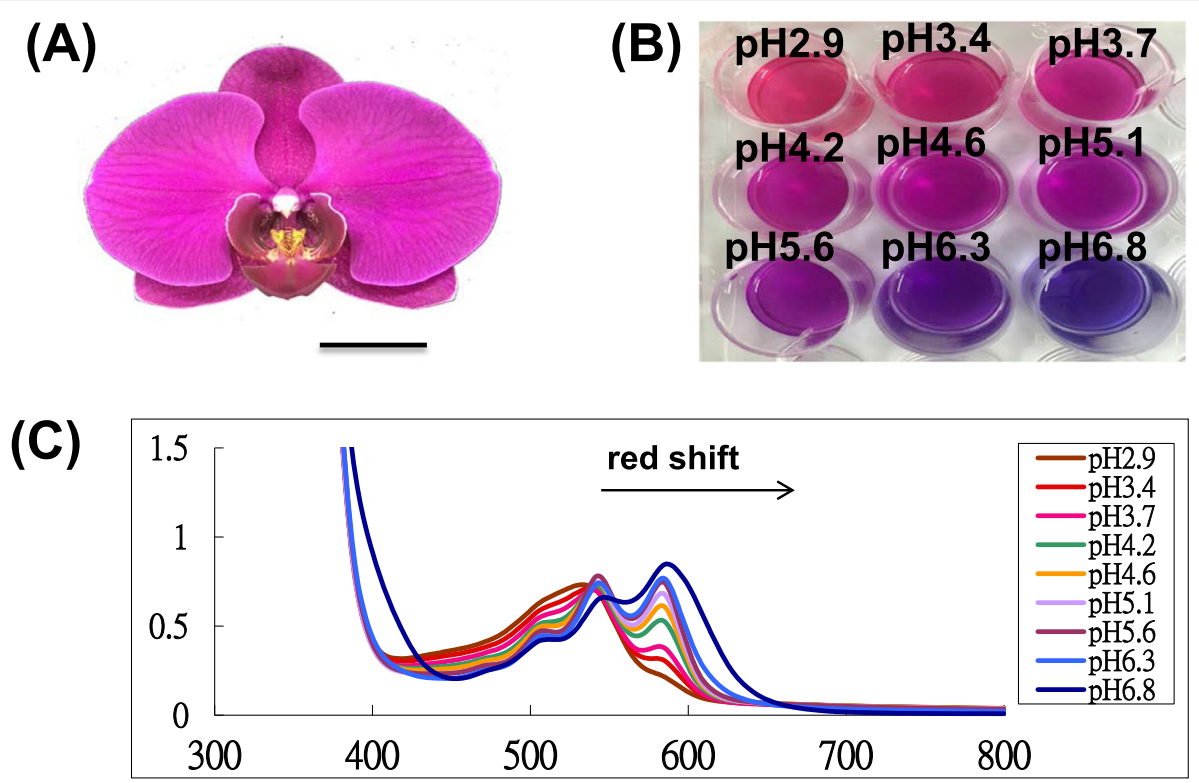

(D)

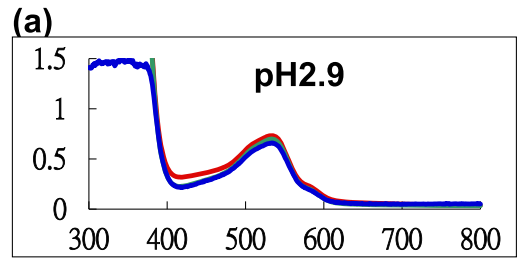

(d)

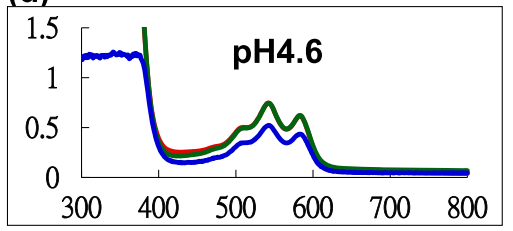

(b)

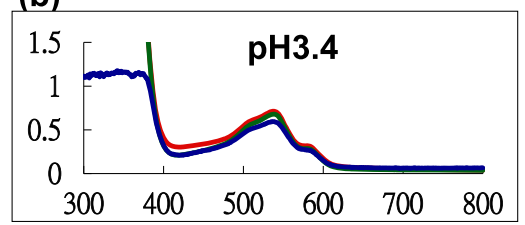

(e)

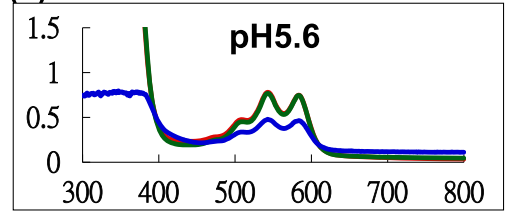

(c)

(f)
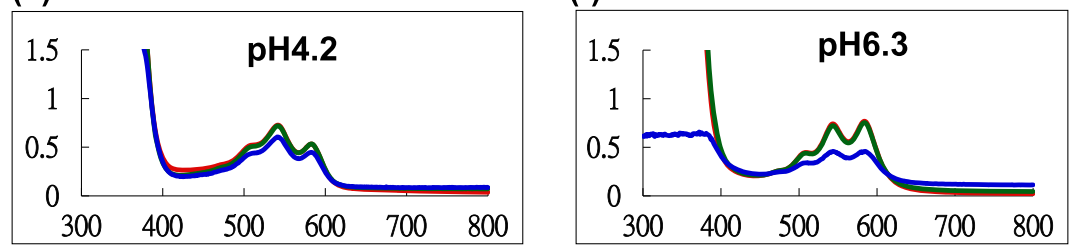

Fig. 8 Absorption spectra of anthocyanin extract from P. Big Chili. (A) Flower of P. Big Chili, (B) anthocyanin extract from flowers of P. Big Chili at different $\mathrm{pH}$ values, (D) absorption spectra of tepal crude extracts at different $\mathrm{pH}$ values. Scale bar is $2.5 \mathrm{~cm}$. (D) Absorption spectra of anthocyanin extract at different times. Visible absorption spectra of tepal crude extracts from P. OX Honey 'OX1372' at various pH values, including (a) 2.9, (b) 3.4, (c) 4.2, (d) 4.6, (e) 5.6, and ( $f$ ) 6.3 incubated for $0 \mathrm{~h}$ (red line), $24 \mathrm{~h}$ (green line) and $96 \mathrm{~h}$ (red line)

anthocyanin was 51 -fold higher in blue than purple flowers [31]. $\mathrm{Fe}^{3+}$ is necessary to form the blue color in cyanidin-based flowers including cornflower and blue poppy [17, 32, 33]. $\mathrm{Mg}^{2+}$ is essential for producing metalloanthocyanin in several plants, including Commelina communis, Centaurea cyanus, Salvia patens, S. uliginosa and Nemophila menziesli [16]. Our results showed that the molar ratio of $\mathrm{Al}^{3+}, \mathrm{Ca}^{2+}$ and $\mathrm{Fe}^{3+}$ metal elements to cyanidin-based anthocyanin was 190-, 49-, and 51-fold higher, respectively, in violet-blue than purple Phalaenopsis.

Interference in protein functions by the substitution of amino acids in SRS domains and substrate orientation The large size of amino acids results in eliminating F3'5'H function. Substitution of Ser to Thr at position 8 of SRS6 can decrease 5'-hydroxylation activity [26]. Similarly, sequence analysis showed Val in PhF3'5'H and 
Table 1 Concentrations of metal elements and anthocyanin and their molar ratio

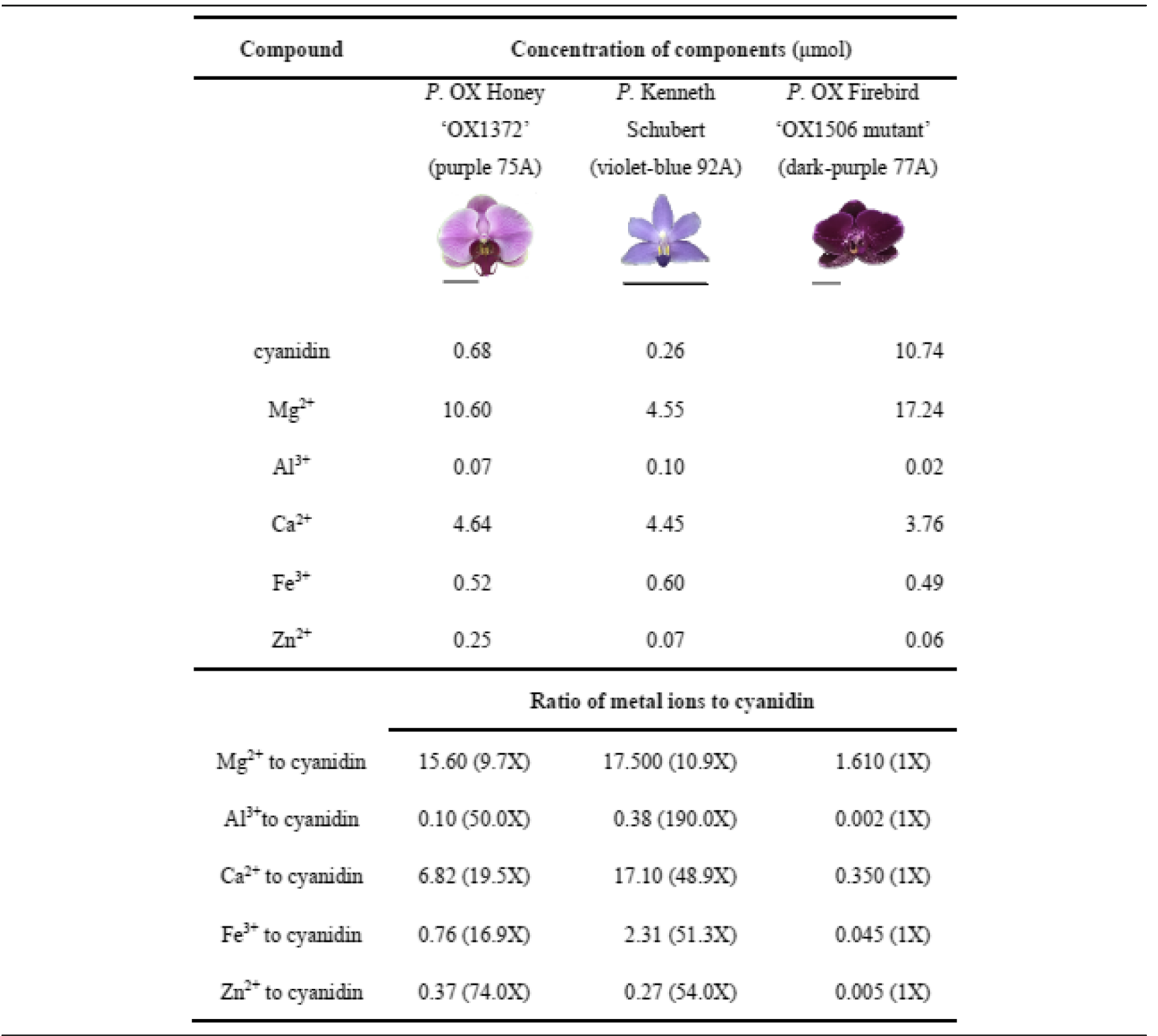

Ala in DgF3'5' $\mathrm{H}$, correspondingly, which may indicate why PhF3'5'H lost the 5'-hydroxylation activity. In addition, replacements of amino acid residues of the SRS4 domain in F3'5'H of soybean (GmaxF3'5'H) could also alter its enzymatic activityby disrupting the contact between heme group and substrate [34]. This affects the conformation of the active site in F3'5' $\mathrm{H}$ and thus change the flower color formation. As compared with the amino acid residues of the SRS4 domain of GmaxF3'5' $\mathrm{H}$, there are more amino acid residues altered in PhF3'5'H than DgF3'5'H [34]. The amino acid sequence of the SRS4 domain in DgF3'5'H is similar to that of GmaxF3'5'H, except Ser300 replaces Thr300. The side-chain of residue 300 points away from that heme; thus, the substitution of this residue does not eliminate the function. Even more amino acid residues are altered in PhF3'5'H. Most side chains of these substitutes in the model structure are located away from the heme, except for Phe294 and Asp297, which are located near the heme; thus, most substitutions do not alter the function. Phe294Leu and Asp297Asn may interfere in the protein function by altering the conformation of active sites via a large size and charge repulsion, respectively.

In addition, results of substrate docking showed that the aromatic rings (B-ring) of N, DHQ and E were oriented toward the N-terminal of SRS4 and SRS1 of PhF3'5'H (Fig. 6), whereas the aromatic rings (B-ring) of $\mathrm{N}, \mathrm{DHQ}$ and $\mathrm{E}$ were oriented toward the C-terminal of SRS4, SRS5 and SRS6 of DgF3'5'H. This finding is similar to previous results in predicting F3'H in Arabidopsis 
thaliana [35]. PhF3'5'H may fail to function because of its unusual direction of substrate binding. Thus, homology modeling and docking can provide a good model to evaluate experimentally tested mutants and as a further rationale for the effect of individual mutants.

\section{True blue Phalaenopsis flowers could be achieved by genetic engineering of the anthocyanin biosynthesis pathway}

Endogenous $F 3^{\prime} H$ must be silenced for high delphinidin accumulation to lead to a blue hue because both $F 3^{\prime} H$ and $F 3^{\prime} 5^{\prime} \mathrm{H}$ compete for the same substrates of $\mathrm{N}$ and DHK [8]. For transgenic chrysanthemum, 80 and 35\% delphinidin accumulated in $F 3^{\prime} 5^{\prime} H$-induced plants with and without endogenous $F 3^{\prime} H$ silenced [8]. Previous studies showed that 80 and $95 \%$ delphinidin accumulated and resulted in purple-violet (N81B) and violet (88C) chrysanthemum [9]. In addition, by overexpressing both heterologous F3'5'H and PhDFR, 94 and $100 \%$ delphinidin accumulation resulted in purple $82 \mathrm{~A}$ and mauve $75 \mathrm{~A}$ groups, respectively, in carnation $[6,7]$. In rose, overexpression of heterologous F3'5' $H$ and PhDFR resulted in a 95\% delphinidin accumulation and the violet group 85B [5]. In our study, overexpression of both PeMYB2 and DgF3'5'H in the V3 tepal caused the highest delphinidin accumulation (53.6\%), and the flower color shifted from white (NN155C) to violet-blue (91A). Even though relatively lower delphinidin accumulation was observed with overexpression of $\mathrm{DgF3} \mathrm{S}^{\prime} \mathrm{H}$ in Phalaenopsis, higher delphinidin accumulation and a bluer violet-blue resulted as compared with other overexpressed plants. This is the first report to show a novel blue hue created in white Phalaenopsis cultivars. Our findings suggest that with the addition of PeMYB2, DgF3'5' $\mathrm{H}$ was able to compete the substrates of $\mathrm{N}$ and DHK with endogenous F3'H in Phalaenopsis to accumulate the delphinidin compound. Silencing endogenous $F 3^{\prime} H$ accompanied by $D g F 3^{\prime} 5^{\prime} H$-induced transgenic Phalaenopsis is required to produce high delphinidin accumulation and a true-blue color formation in Phalaenopsis.

Different strategies of genetic regulation in the anthocyanin biosynthesis pathway have been used [36]. Heterologous $F 3^{\prime} 5^{\prime} H$ and also PhDFR were introduced into host plants of rose and carnation. PhDFR strongly utilizes dihydromyricetin (DHM) but not DHK, thereby benefiting delphinidin production [5-7]. In contrast, to produce blue chrysanthemum, heterologous $F 3^{\prime} 5^{\prime} H$ was introduced, and endogenous $F 3^{\prime} H$ was silenced. Knockdown of $F 3^{\prime} H$ can increase delphinidin production [8]. Of note, for the strategy adopted in chrysanthemum, only the suitable promoter of chrysanthemum F3H was used to drive efficient heterologous expression of F3'5' $\mathrm{H}$ without modifying other structure genes in the anthocyanin biosynthesis pathway and led to a high production of delphinidin and accumulation in transgenic chrysanthemum [9]. These cases were all successful in causing a high production of at least $80 \%$ delphinidin by regulating the anthocyanin biosynthesis pathway and leading to a novel blue hue.

In conclusion, we proved the initial assumption framework of how white-color orchids are converted to blue hue by overexpressing an anthocyanin regulating $M Y B$ transcription factor, $P e M Y B 2$, and heterologous $F 3^{\prime} 5^{\prime} H$ $\left(D g F 3^{\prime} 5^{\prime} H\right)$ while knocking down the expression of endogenous $F 3^{\prime} H$. This can set the ground work for molecular breeding of Phalaenopsis cultivars with real blue pigment.

\section{Conclusions}

The violet-blue color formation in Phalaenopsis was caused by both reduced vacuolar acidification and enhanced molar ratio between $\mathrm{Ca}^{2+}$ and $\mathrm{Fe}^{3+}$ to cyanidinbased anthocyanin. Delphinidin did not accumulate in any colors of Phalaenopsis cultivars because of the altered amino acids and possibly adverse substrate binding direction, $P h F 3^{\prime} 5^{\prime} H$ has little to no ability for delphinidin accumulation. On overexpressing both $D g F 3^{\prime} 5^{\prime} H$ and PeMYB2, we observed a novel violet-blue color in the white Phalaenopsis cultivar, with 53.6\% delphinidin and $46.3 \%$ cyanidin accumulation. This study will benefit the understanding of the regulatory mechanism of violetblue color formation and set the groundwork for molecular breeding of Phalaenopsis cultivars with novel blue color pigmentation.

\section{Methods}

Plant materials

For color analysis, Phalaenopsis cultivars with various colors including red-purple, purple, purple-violet, violet, violet-blue and white were collected from various local orchid nurseries (Additional file 1). For comparison, blue Delphinium grandiflorum was collected from Ruifeng Horticulture (Changhua, Taiwan) (Additional file 2). Among the Phalaenopsis cultivars, P. OX Brother Seamate 'OX1313' with white sepals/petals and red-purple lip, purple $P$. OX Honey 'OX1372' and dark-purple $P$. OX Firebird 'OX1506 mutant' were collected from OX Orchids Farm (Tainan, Taiwan). Purple $P$. hybrid 'King Car' was collected from King Car Biotechnology Industrial Co. (Ilan, Taiwan). Purple-violet $P$. Big Chili, white $P$. aphrodite subsp. formosana, and white $P$. Sogo Yukidian 'V3' were collected from Taiwan Sugar Corp. (Tainan, Taiwan). Violet $P$. violacea 'Indigo Blue' was collected from Meidarland Orchids (Tainan, Taiwan). Violet $P$. (Germaine Vincent x Samera 'indigo') 'S304' was collected from Keng-Liang Liu Orchid Nursery (Kaohsiung, Taiwan). Violet $P$. (Kenneth Schubert $\mathrm{x}$ 
Samera) 'KS1226' and Violet-blue P. Purple Martin were collected from Kung Sir Orchids (Tainan, Taiwan). Violet-blue $P$. tau Chiang Sapphire was collected from Sunhope Garden Biotec (Tainan, Taiwan). Violet-blue $P$. Kenneth Schubert was collected from Taida Horticultural Co. (Changhua, Taiwan). The white $P$. Sogo Yukidian 'V3' and purple $P$. OX Honey 'OX1372' were used for transient overexpression analysis because their colors of tepals were beneficial for delphinidin accumulation and blue color. All plant materials were collected according to institutional guidelines and grown in the greenhouse at Nation Cheng Kung University (NCK, Tainan, Taiwan) under natural light and at $23-27^{\circ} \mathrm{C}$. All plant materials used in this study including the Phalaenopsis cultivars and Delphinium grandiflorum are commercially available, not collected from the wild. All plant materials were kept in permissible green house at NCKU. Experimental research on plants comply with institutional, national, or international guidelines. The authenticity of these materials has been verified by each orchid nursery owners.

\section{Definition of flower colors}

For the red-purple series of plant materials, their colors ranged from red-purple, purple, purple-violet, violet and violet-blue in Phalaenopsis (Additional file 1). To define the colors, the Royal Horticultural Society Color Chart was used. Lip color of $P$. OX Brother Seamate 'OX1313' is classified in the red-purple 71A group (Additional file 2). $P$. OX Honey 'OX1372', P. OX Firebird 'OX1506 mutant' and $P$. hybrid 'King Car' are classified in the purple 75A, 77A and N78C groups, respectively (Additional file 2). $P$. Big Chili is classified in the purple-violet N80A group (Additional file 2). P. violacea Indigo blue', P. (Germaine Vincent x Samera 'indigo') 'S304' and $P$. (Kenneth Schubert $x$ Samera) 'KS1226' are classified in the violet 86A, N87A and N87B groups, respectively (Additional file 2). $P$. tau Chiang Sapphire, $P$. Purple Martin and $P$. Kenneth Schubert are classified in the violet-blue 90A, 90B and 92A groups, respectively (Additional file 2). P. aphrodite subsp. formosana and $P$. Sogo Yukidain 'V3' are both classified in the white NN155C group (Additional file 2). For comparison, Delphinium grandiflorum is classified in the blue 101A group (Additional file 2).

\section{Extraction of anthocyanin}

Four days post transient overexpression in V3 flowers, anthocyanins were extracted as previously described and quantified with HPLC approach [37]. Briefly, the ground sample powders were extracted with methanol supplied with $1 \%(\mathrm{v} / \mathrm{v}) \mathrm{HCl}$ at $4{ }^{\circ} \mathrm{C}$ for $20 \mathrm{~h}$. The samples were then centrifuged at $10,000 \mathrm{Xg}$ for $20 \mathrm{~min}$ at $4{ }^{\circ} \mathrm{C}$. The supernatant was dried using a vacuum concentrator, and the pellet was resolved in $2 \mathrm{~N} \mathrm{HCl}$ and hydrolyzed the glycosyl group at $100^{\circ} \mathrm{C}$ for $1 \mathrm{~h}$. The hydrolyzed samples were retrieved through the solid-phase DSC-18 SPE extraction column (Supelco, SL, USA) and then eluted in methanol supplied with $1 \%(\mathrm{v} / \mathrm{v}) \mathrm{HCl}$. The eluents were stored at $-20^{\circ} \mathrm{C}$ for HPLC analysis. We used $250 \times 4.6$ mm Hypersil BDS C18 column (Thermo Fisher Scientific, MA, USA) for HPLC separation (Hitachi d-7000, 1-7100, L7200, and L7420). Solvent A (formic acid: water $=1: 99$ $[\mathrm{v} / \mathrm{v}])$ and solvent $C(100 \%$ methanol) were mixed at a flow rate of $1.0 \mathrm{ml} / \mathrm{min}$ for compound resolution. Anthocyanins were detected at the $530 \mathrm{~nm}$ wavelength. Cyanidin (Sigma-Aldrich, SL, USA) was recruited as a standard in HPLC analysis. Three biological repeats were performed for each overexpression experiments, and repeated transient assays twice independently.

\section{RNA extraction and reverse transcription to CDNA}

Sepals and petals of 1 - to $2.5-\mathrm{cm}$ floral buds were collected, submerged in liquid nitrogen and then stored at $-80^{\circ} \mathrm{C}$ for RNA extraction. Total RNA was extracted as described previously by using guanidium thiocyanate method [37]. Residual DNA was removed by treating with RNase-Free DNase I (New England Biolabs, MA, USA). Reverse transcription to cDNA was performed using SuperScript III (Invitrogen, CA, USA).

\section{qRT-PCR}

For each gene, primer pairs were designed within the gene-specific regions (Additional file 3). q-PCR by amplification of cDNA with a fluorescent SYBR Green PCR Master Mix (Applied Biosystems, MA, USA) dye were used to measure gene expression and detected by an ABI Prism 7000 Sequence Detection System (Applied Biosystems, MA, USA). Reactions were performed at $95^{\circ} \mathrm{C}$ for $10 \mathrm{~min}$ and repeated cycling for 40 cycles $\left(95^{\circ} \mathrm{C}\right.$ for $15 \mathrm{~s}$ and $60^{\circ} \mathrm{C}$ for $\left.1 \mathrm{~min}\right)$. After magnification, melting curve analysis was used to verify primer dimer formation and amplicon specificity. PeActin4 (AY134752), a housekeeping gene, was used for normalization of qRT-PCR results [38]. Each sample was analyzed in technical triplicate. Data are presented as mean \pm SD of three technical replicates and three independently biological samples performed.

\section{Sequence alignment and phylogenetic analysis}

Sequence alignment involved using Align X (Vector NTI Suite, V.8, Invitrogen, Carlsbad, CA, USA). Phylogenetic analysis trees were constructed with the neighborjoining method and evaluated by bootstrap analysis with MEGA5 [39], with 1000 bootstrapping datasets to estimate the confidence of each tree clade. Two different phylogenetic trees were constructed: one was constructed with sequences of $7 \mathrm{~F} 3^{\prime} \mathrm{Hs}, 7 \mathrm{~F} 3^{\prime} 5^{\prime} \mathrm{Hs}$ and 2 FLSIIs and the other was constructed with sequences of 
23 ATPases. Sequences of F3'Hs, F3'5'Hs, FLSIIs, and ATPases from other plants were acquired from GenBank (http://www.ncbi.nlm.nih.gov/), with the following accession numbers: Campanula medium F3'5'H (D14590), Catharanthus roseus F3'5'H (AJ011862), Eustoma grandiflorum F3'5'H (D14589), Petunia hybrida F3'5'H (Z22544), Delphinium grandiflorum F3'5'H (AY856345), Vitis amurensis F3'5'H (FJ645756.1), Petunia hybrida F3'H (AF155332), Torenia hybrid cultivar F3'H (AB057673), Chrysanthemum morifolium F3'H (AB523844.1), Glycine max F3'H (AB191404), Narcissus tazetta F3'H (JX292106.1), Arachis hypogaea F3'H (JN572892.1), Antirrhinum majus FNSII (AB028151), Callistephus chinensis FNSII (AF188612), Arabidopsis thaliana AtAHA2 (AEE85731.1), Arabidopsis thaliana AtAHA4 (Q9SU58.2), Nicotiana plumbaginifolia NPPMA1 (AAA34094), Petunia $x$ hybrida PhPH5 (DQ334807), Nicotiana plumbaginifolia NpPMA9 (AF156684), Populus trichocarpa PtAHA10-like (XP_002326625.1), Vitis vinifera VvAHA10-like (CBI35782), Oryza sativa OsAHA9 (AJ440220), Arabidopsis thaliana AtAHA10 (NP173169), Citrobacter sp. CsMgtA (ZP04559661), Escherichia coli EcMgtA (YP672334), Klebsiella pneumoniae KpMgtA (YP002917472), Petunia $x$ hybrida PhPH1 (AHH24342.1), Vitis vinifera VvPH1-like (CBI41039), Ricinus communis RcPH1-like (XP002533565), Populus trichocarpa PtPH1like (XP002306511), Arabidopsis thaliana AtACA2 (NP195497) and Oryza sativa Os03g0616400 (NP001050661).

\section{Molecular modeling and docking}

The prediction of F3'5' $\mathrm{H}$ tertiary protein structures involved using SWISS-MODELL (https://swissmodel. expasy.org/). The X-ray crystal of P450 1A2 (PDB ID: 2hi4.1) was used as the template [40]. Next, the prediction of docking between the F3'5'H protein structure and substrates involved using SwissDock (http://www. swissdock.ch/docking). Finally, UCSF Chimera was used to visualize the predicted binding model [41].

\section{Transient overexpression of heterologous $\mathrm{F3}^{\prime} \mathrm{5}^{\prime} \mathrm{Hs}$ and PeMYB2 in Phalaenopsis flowers}

For transient overexpression of PeMYB2 and PhF3'5' $H$ or $D g F 3^{\prime} 5^{\prime} \mathrm{H}$ in white-flower $\mathrm{V} 3$, the binary vector p1304NhXb containing duplicated Cauliflower mosaic virus (CaMV) 35S promoter was used following Hsu et al., (2015) [22]. Briefly, these genes were PCRamplified and digested with restriction enzyme XhoI, and then ligated to p1304NhXb. The recombinant constructs were bombarded into Agrobacterium tumefaciens EHA105 using electroproration. The engineered $A$. tumefaciens was grown at $28^{\circ} \mathrm{C}$ overnight, refreshed culture to $\mathrm{OD}_{600}=0.8-1$, and then harvested by centrifugation. Cell pellets were resuspended in Murashige and Skoog medium supplied with $100 \mu \mathrm{M}$ acetosyringone, and incubated at room temperature for $30 \mathrm{~min}$. The bacterial suspensions were infiltrated into the base of sepals and petals of V3 flowers, and incubated at $25^{\circ} \mathrm{C}$ with a $10 \mathrm{~h}$ light $/ 14 \mathrm{~h}$ dark photoperiod. Five days post bombardment, the infiltrated flowers were photographed and then stored at $-80^{\circ} \mathrm{C}$ for anthocyanin extraction. The transient overexpression assay was performed in five different plants for each experiment, and repeated three times independently.

\section{$\mathrm{pH}$ value measurement and visible absorption spectra of corolla homogenates}

The complete petals of flowers were directly ground, centrifuged at $13,000 \mathrm{rpm}$ (Heraeus Biofuge Pico, Germany) for $15 \mathrm{~min}$, then supernatant was immediately measured by using a pH electrode (Van London Co., TX, USA). In addition, the flower sap was diluted in 1 $\mathrm{ml}$ buffer solution containing $0.2 \mathrm{M}$ sodium phosphate dibasic $\left(\mathrm{Na}_{2} \mathrm{HPO}_{4}\right)$ and $0.1 \mathrm{M}$ citric acid $\left(\mathrm{C}_{6} \mathrm{H}_{8} \mathrm{O}_{7}\right)$ at various $\mathrm{pH}$ values and measured by spectrophotometric analysis from OD 300-800 nm (Biochrom Libra S50, UK).

\section{Metal ion measurement of the colorful petals}

Powders of colorful petals were dried by using a freeze dryer (MILLROCK LYOBT85, USA), then ground by using a homogenizer (QIAGEN Schwingmuhle TissueLyser 2, Germany). Next, $100 \mathrm{mg}$ of the dried sample was digested in $5 \mathrm{ml}$ of $70 \% \mathrm{HNO}_{3}$ and $0.5 \mathrm{ml} 30 \% \mathrm{H}_{2} \mathrm{O}_{2}$ for high-performance microwave treatment (CEM, MARS Xpress 5, Matthews, NC, USA) at 400 watts and increased to $180^{\circ} \mathrm{C}$ within $15 \mathrm{~min}$ and sustained for 15 min. After digestion, samples were diluted with $2 \%$ $\mathrm{HNO}_{3}$ for metal ion measurement by using ICP-MS analysis (Agilent $7500 \mathrm{cx}$, USA). High-performance microwave and ICP-MS were both performed at the Institute of Biomedical Engineering and Nanomedicine of National Health Research Institutes (Miaoli, Taiwan).

\section{Statistical analysis}

The correlation between the concentration of metal ion and violet blue color formation and $\mathrm{pH}$ value and violet blue color formation were analyzed statistically with Pearson's correlation coefficient [42].

\section{Supplementary information}

Supplementary information accompanies this paper at https://doi.org/10 1186/s12870-020-02402-7.

Additional file 1: Flowers used in this study, and their definition of color code. Flower color of Phalaenopsis and Delphinium hybrid were assigned according to the Royal Horticultural Society Color Chart.

Additional file 2: Flower color of various flowering development stages of violet-blue $P$. Kenneth Schubert and $P$. Purple Martin.(A) P. Kenneth Schubert in various flowering development stages range from flower opening (D) and after flower opening 5 days $(D+5), 10$ days $(D+10), 15$ 
days $(D+15)$, and 20 days $(D+20)$. (B) Flowers of $P$. Kenneth Schubert and, (C) the whole plant of $P$. Purple Martin. Scale bar is $2.5 \mathrm{~cm}$.

Additional file 3: Primers used in this study. List of primers for $q R T P C R$, gene isolation, 5' and $3^{\prime}$ RACE.

\section{Abbreviations}

ANS: Anthocyanin synthase; DFR: Dihydroflavonol-4-reductase; DHF: Dihydroflavonols; DHK: Dihydrokaempferol; DHQ: Dihydroquercetin; E: Eriodictyol; F3'5'H: Flavonoid 3', 5'-hydroxylase; F3'H: Flavonoid 3'hydroxylase; F3H: Flavonoid 3-hydroxylase; HPLC: High-performance liquid chromatography; ICP-MS: Inductively coupled plasma mass spectrometry; N: Naringenin; RACE: Rapid amplification of CDNA ends; RHSCC: Royal horticultural society color chart; SRS: Substrate recognition site; VIGS: Virusinduced gene silencing; V3: Phalaenopsis Sogo Yukidian V3'

\section{Acknowledgments}

We thank Dr. Ping-Chung Kuo (School of Pharmacy, National Cheng Kung University, Taiwan) for helpful discussions and critical reading of the manuscript. We acknowledge the technical services provided by the ICP-MS analysis at the National Health Research Institute of Biomedical Engineering and Nanomedicine (Miaoli, Taiwan). We also acknowledge the plant materials provided from the various local orchid nurseries including Flower nursery (TianWei, Changhua, Taiwan); OX Orchids Farm (Tainan, Taiwan); King Car Biotechnology Industrial Co. (llan, Taiwan); Taiwan Sugar Corp. (Tainan); Meidarland Orchids (Tainan); Keng-Liang Liu orchid nursery (Kaohsiung, Taiwan); Kung Sir Orchids (Tainan); Sunhope Garden Biotec (Tainan) and Taida Horticultural Co. (Changhua, Taiwan).

\section{Authors' contributions}

$\mathrm{CYL}, \mathrm{CCH}, \mathrm{WHC}$ and $\mathrm{HHC}$ conceived the project and designed research; $\mathrm{CYL}$, KPR and MFJ performed research; CYL, LMH, MFJ and HHC analyzed data and wrote the paper; all authors reviewed and approved the manuscript for publication.

\section{Funding}

This work was supported by the Ministry of Science and Technology of Taiwan (MOST 108-2811-B-006-531-). The funding body did not play a role in the design research, measurements, data analysis, and drafted the manuscript, but just provide the financial support.

\section{Availability of data and materials}

The datasets used and/or analysed during the current study available from the corresponding author on reasonable request.

\section{Ethics approval and consent to participate}

Not applicable.

\section{Consent for publication}

Not applicable.

\section{Competing interests}

The authors declare that they have no competing interests.

\section{Author details}

'Department of Life Sciences, National Cheng Kung University, Tainan 701, Taiwan. ${ }^{2}$ Orchid Research and Development Center, National Cheng Kung University, Tainan 701, Taiwan. ${ }^{3}$ Nantou City, Taiwan.

\section{Received: 8 February 2020 Accepted: 22 April 2020}

\section{Published online: 12 May 2020}

\section{References}

1. Rausher MD. The science of flavonoids. In: Grotewold E, editor. The evolution of flavonoids and their genes. New York: Springer; 2006. p. 175211.

2. Tanaka Y, Sasaki N, Ohmiya A. Biosynthesis of plant pigments: anthocyanins, betalains and carotenoids. Plant J. 2008;54(4):733-49.

3. Holton TA, Cornish EC. Genetics and biochemistry of anthocyanin biosynthesis. Plant Cell. 1995;7(7):1071-83.
4. Springob K, Nakajima J, Yamazaki M, Saito K. Recent advances in the biosynthesis and accumulation of anthocyanins. Nat Prod Rep. 2003;20(3): 288-303.

5. Katsumoto Y, Fukuchi-Mizutani M, Fukui Y, Brugliera F, Holton TA, Karan M, Nakamura N, Yonekura-Sakakibara K, Togami J, Pigeaire A, et al. Engineering of the rose flavonoid biosynthetic pathway successfully generated bluehued flowers accumulating delphinidin. Plant Cell Physiol. 2007:48(11):1589600.

6. Tanaka Y, Tsuda S, Kusumi T. Metabolic engineering to modify flower color. Plant Cell Physiol. 1998;39(11):1119-26.

7. Fukui $Y$, Tanaka Y, Kusumi T, Iwashita T, Nomoto K. A rationale for the shift in colour towards blue in transgenic carnation flowers expressing the flavonoid 3 ',5' '-hydroxylase gene. Phytochemistry. 2003;63(1):15-23.

8. Brugliera F, Tao GQ, Tems U, Kalc G, Mouradova E, Price K, Stevenson K, Nakamura N, Stacey I, Katsumoto Y, et al. Violet/blue chrysanthemumsmetabolic engineering of the anthocyanin biosynthetic pathway results in novel petal colors. Plant Cell Physiol. 2013;54(10):1696-710.

9. Noda N, Aida R, Kishimoto S, Ishiguro K, Fukuchi-Mizutani M, Tanaka Y, Ohmiya A. Genetic engineering of novel bluer-colored chrysanthemums produced by accumulation of Delphinidin-based Anthocyanins. Plant Cell Physiol. 2013;54(10):1684-95.

10. Yoshida K, Kondo T, Okazaki Y, Katou K. Cause of blue petal color. Nature. 1995;373(6512):291.

11. Yoshida K, Kawachi M, Mori M, Maeshima M, Kondo M, Nishimura M, Kondo T. The involvement of tonoplast proton pumps and $\mathrm{Na}+(\mathrm{K}+) / \mathrm{H}+$ exchangers in the change of petal color during flower opening of morning glory, Ipomoea tricolor cv. Heavenly Blue. Plant Cell Physiol. 2005;46(3):407-15.

12. Ohnishi M, Fukada-Tanaka S, Hoshino A, Takada J, Inagaki Y, lida S. Characterization of a novel $\mathrm{Na}+/ \mathrm{H}+$ antiporter gene InNHX2 and comparison of InNHX2 with InNHX1, which is responsible for blue flower coloration by increasing the vacuolar $\mathrm{pH}$ in the Japanese morning glory. Plant Cell Physiol. 2005:46(2):259-67.

13. Noda N. Recent advances in the research and development of blue flowers. Breed Sci. 2018;68(1):79-87.

14. Verweij W, Spelt C, Di Sansebastiano GP, Vermeer J, Reale L, Ferranti F, Koes R, Quattrocchio F. An H+ P-ATPase on the tonoplast determines vacuolar $\mathrm{pH}$ and flower colour. Nat Cell Biol. 2008;10(12):1456-62.

15. Faraco M, Spelt C, Bliek M, Verweij W, Hoshino A, Espen L, Prinsi B, Jaarsma $R$, Tarhan $E$, de Boer AH, et al. Hyperacidification of vacuoles by the combined action of two different P-ATPases in the Tonoplast determines flower color. Cell Rep. 2014;6(1):32-43.

16. Yoshida K, Mori M, Kondo T. Blue flower color development by anthocyanins: from chemical structure to cell physiology. Nat Prod Rep. 2009:26(7):884-915.

17. Yoshida K, Kitahara S, Ito D, Kondo T. Ferric ions involved in the flower color development of the Himalayan blue poppy, Meconopsis grandis. Phytochemistry. 2006;67(10):992-8.

18. Takeda K. Blue metal complex pigments involved in blue flower color. Proc Jpn Acad Ser B Phys Biol Sci. 2006;82(4):142-54.

19. Schwinn K, Venail J, Shang YJ, Mackay S, Alm V, Butelli E, Oyama R, Bailey P, Davies K, Martin C. A small family of MYB-regulatory genes controls floral pigmentation intensity and patterning in the genus Antirrhinum. Plant Cell. 2006;18(4):831-51.

20. Davies KM, Albert NW, Schwinn KE. From landing lights to mimicry: the molecular regulation of flower colouration and mechanisms for pigmentation patterning. Funct Plant Biol. 2012;39(8):619-38.

21. Albert NW, Lewis DH, Zhang H, Schwinn KE, Jameson PE, Davies KM. Members of an R2R3-MYB transcription factor family in Petunia are developmentally and environmentally regulated to control complex floral and vegetative pigmentation patterning. Plant J. 2011;65(5):771-84.

22. Hsu CC, Chen YY, Tsai WC, Chen WH, Chen HH. Three R2R3-MYB transcription factors regulate distinct floral pigmentation patterning in Phalaenopsis spp. Plant Physiol. 2015;168(1):175-U910.

23. Fu CH, Chen YW, Hsiao YY, Pan ZJ, Liu ZJ, Huang YM, Tsai WC, Chen HH. OrchidBase: a collection of sequences of the Transcriptome derived from orchids. Plant Cell Physiol. 2011;52(2):238-43.

24. Tsai WC, Fu CH, Hsiao YY, Huang YM, Chen LJ, Wang MN, Liu ZJ, Chen HH. OrchidBase 2.0: Comprehensive Collection of Orchidaceae Floral Transcriptomes. Plant Cell Physiol. 2013;54(2):e7.

25. Gotoh $\mathrm{O}$. Substrate recognition sites in cytochrome P450 family 2 (CYP2) proteins inferred from comparative analyses of amino acid and coding nucleotide sequences. J Biol Chem. 1992;267(1):83-90. 
26. Seitz $\mathrm{C}$, Ameres $\mathrm{S}$, Forkmann $\mathrm{G}$. Identification of the molecular basis for the functional difference between flavonoid 3 '-hydroxylase and flavonoid 3',5 '-hydroxylase. FEBS Lett. 2007;581(18):3429-34.

27. Seitz C, Ameres S, Schlangen $K$, Forkmann G, Halbwirth H. Multiple evolution of flavonoid 3',5'-hydroxylase. Planta. 2015;242(3):561-73.

28. Yoshida K, Toyama-Kato Y, Kameda K, Kondo T. Sepal color variation of Hydrangea macrophylla and vacuolar $\mathrm{pH}$ measured with a proton-selective microelectrode. Plant Cell Physiol. 2003;44(3):262-8.

29. Shoji K, Miki N, Nakajima N, Momonoi K, Kato C, Yoshida K. Perianth bottom-specific blue color development in tulip cv. Murasakizuisho requires ferric ions. Plant Cell Physiol. 2007;48(2):243-51.

30. Ito D, Shinkai Y, Kato Y, Kondo T, Yoshida K. Chemical studies on different color development in blue- and red-colored sepal cells of Hydrangea macrophylla. Biosci Biotechnol Biochem. 2009;73(5):1054-9.

31. Yoshida K, Negishi T. The identification of a vacuolar iron transporter involved in the blue coloration of cornflower petals. Phytochemistry. 2013; 94:60-7.

32. Kondo T, Ueda M, Isobe M, Goto T. A new molecular mechanism of blue color development with protocyanin a supramolecular pigment from cornflower, Centaurea cyanus. Tetrahedron Lett. 1998;39(45):8307-10.

33. Shiono M, Matsugaki N, Takeda K. Structure of the blue cornflower pigment - packaging red-rose anthocyanin as part of a 'superpigment' in another flower turns it brilliant blue. Nature. 2005;436(7052):791.

34. Sundaramoorthy J, Park GT, Chang JH, Lee JD, Kim JH, Seo HS, Chung G, Song JT. Identification and Molecular Analysis of Four New Alleles at the W1 Locus Associated with Flower Color in Soybean. PLoS One. 2016;11:7.

35. Rupasinghe S, Baudry J, Schuler MA. Common active site architecture and binding strategy of four phenylpropanoid P450s from Arabidopsis thaliana as revealed by molecular modeling. Protein Eng. 2003;16(10):721-31.

36. Sasaki N, Nakayama T. Achievements and perspectives in biochemistry concerning anthocyanin modification for blue flower coloration. Plant Cell Physiol. 2015;56(1):28-40.

37. Hsu CC, Su CJ, Jeng MF, Chen WH, Chen HH. A HORT1 Retrotransposon insertion in the PeMYB11 promoter causes harlequin/black flowers in Phalaenopsis orchids. Plant Physiol. 2019:180(3):1535-48.

38. Chen YH, Tsai YJ, Huang JZ, Chen FC. Transcription analysis of peloric mutants of Phalaenopsis orchids derived from tissue culture. Cell Res. 2005; 15(8):639-57.

39. Tamura K, Peterson D, Peterson N, Stecher G, Nei M, Kumar S. MEGA5: molecular evolutionary genetics analysis using maximum likelihood, evolutionary distance, and maximum parsimony methods. Mol Biol Evol. 2011;28(10):2731-9.

40. Sansen S, Yano JK, Reynald RL, Schoch GA, Griffin KJ, Stout CD, Johnson EF. Adaptations for the oxidation of polycyclic aromatic hydrocarbons exhibited by the structure of human P450 1A2. J Biol Chem. 2007;282(19):14348-55.

41. Pettersen EF, Goddard TD, Huang CC, Couch GS, Greenblatt DM, Meng EC, Ferrin TE. UCSF chimera - a visualization system for exploratory research and analysis. J Comput Chem. 2004;25(13):1605-12.

42. Pearson K. Encyclopedia of public health. In: Kirch W, editor. Pearson's correlation coefficient. Dordrecht: Springer; 2008. p. 1090-1.

\section{Publisher's Note}

Springer Nature remains neutral with regard to jurisdictional claims in published maps and institutional affiliations.

Ready to submit your research? Choose BMC and benefit from:
- fast, convenient online submission
- thorough peer review by experienced researchers in your field
- rapid publication on acceptance
- support for research data, including large and complex data types
- gold Open Access which fosters wider collaboration and increased citations
- maximum visibility for your research: over 100M website views per year
At BMC, research is always in progress.
Learn more biomedcentral.com/submissions

